\title{
Validation of Advanced Computer Codes for VVER Technology: LB-LOCA Transient in PSB-VVER Facility
}

\author{
A. Del Nevo, ${ }^{1}$ M. Adorni, ${ }^{1}$ F. D’Auria, ${ }^{1}$ O. I. Melikhov, ${ }^{2}$ I. V. Elkin, ${ }^{2}$ V. I. Schekoldin, ${ }^{3}$ \\ M. O. Zakutaev, ${ }^{3}$ S. I. Zaitsev, ${ }^{3}$ and M. Benčík ${ }^{4}$ \\ ${ }^{1}$ GRNSPG, University of Pisa, Livornese street 1291, San Piero a Grado, 56126 Pisa, Italy \\ ${ }^{2}$ TH Division, Electrogorsk Research and Engineering Centre, Elektrogorsk, Russia \\ ${ }^{3}$ FSUE EDO “GIDROPRESS", Podolsk, Russia \\ ${ }^{4}$ TH Analyses Department, Nuclear Research Institute Řež, 25068 Řež, Czech Republic
}

Correspondence should be addressed to A. Del Nevo, alessandro.delnevo@enea.it

Received 9 May 2011; Accepted 15 September 2011

Academic Editor: Klaus Umminger

Copyright ( 92012 A. Del Nevo et al. This is an open access article distributed under the Creative Commons Attribution License, which permits unrestricted use, distribution, and reproduction in any medium, provided the original work is properly cited.

\begin{abstract}
The OECD/NEA PSB-VVER project provided unique and useful experimental data for code validation from PSB-VVER test facility. This facility represents the scaled-down layout of the Russian-designed pressurized water reactor, namely, VVER-1000. Five experiments were executed, dealing with loss of coolant scenarios (small, intermediate, and large break loss of coolant accidents), a primary-to-secondary leak, and a parametric study (natural circulation test) aimed at characterizing the VVER system at reduced mass inventory conditions. The comparative analysis, presented in the paper, regards the large break loss of coolant accident experiment. Four participants from three different institutions were involved in the benchmark and applied their own models and set up for four different thermal-hydraulic system codes. The benchmark demonstrated the performances of such codes in predicting phenomena relevant for safety on the basis of fixed criteria.
\end{abstract}

\section{Introductory Remarks}

VVER reactors have some unique and specific features (e.g., large primary and secondary side fluid inventory, horizontal steam generators, and core design), which require dedicated experimental and numerical analyses in order to assess the performance of safety systems and the effectiveness of eventual accident management strategies. The predictive capabilities of computer codes used in reactor safety analysis needs be validated against relevant experimental data, prior to their application to simulate the behavior of a nuclear power plant. To this purpose a "VVER code validation matrix" [1] was developed in the framework of the OECD/NEA activities, based on the experience of the validation matrices for light water reactor already developed in the 80 and then extended in the 90 [2-5].

\section{The PSB-VVER Project}

The OECD/NEA PSB-VVER project (2003-2008) has been set with the objective to obtain the required experimental data not covered by the VVER validation matrix [1]. A test matrix was defined considering the inputs received by the Russian Safety Authority Gosatomnadzor [6]. Five tests were executed in PSB-VVER integral test facility, operated at Electrogorsk Research and Engineering Centre, Elektrogorsk (EREC) [7], which are briefly outlined below and summarized in Table 1. The main objectives of the experiments were as follows:

(i) to generate experimental data in order to validate computer codes for transient analysis of VVER reactors,

(ii) to address the scaling issue,

(iii) to contribute to the investigations of postulated accident scenario and actual phenomena occurring VVER-1000,

(iv) to support safety assessments for VVER-1000 reactors.

The first experiment is an intermediate break loss of coolant accident, that is, $11 \%$ upper plenum break. It simulates 
TABLE 1: OECD/NEA PSB-VVER project: test matrix.

\begin{tabular}{|c|c|c|c|c|c|}
\hline Number & ID & Test & Main phenomena under investigation & Justification & Note \\
\hline (1) & UP-11-08 & $\begin{array}{c}11 \% \text { upper plenum } \\
\text { break" }\end{array}$ & $\begin{array}{l}\text { Break flow } \\
\text { Two-phase natural circulation } \\
\text { Phase separation without mixture level } \\
\text { formation } \\
\text { Entrainment in the core } \\
\text { ECCS mixing and condensation } \\
\text { Heat transfer in steam generator } \\
\text { Flow stratification in horizontal pipes } \\
\text { Heat transfer in the covered core } \\
\text { Heat transfer in uncovered core } \\
\text { (dryout) } \\
\text { Rewet } \\
\text { Thermal-hydraulics in pressurizer }\end{array}$ & $\begin{array}{l}\text { Identification of similarities } \\
\text { and differences in } \\
\text { processes/phenomena } \\
\text { behaviour at ISB-VVER and } \\
\text { PSB-VVER (i.e., } \\
\text { manifestation of "scaling } \\
\text { effect") and their } \\
\text { quantitative characterization }\end{array}$ & $\begin{array}{l}\text { Similar test of } \\
\text { the ISB-VVER } \\
\text { test }\end{array}$ \\
\hline (2) & NC-1 & Natural circulation & $\begin{array}{l}\text { Single-phase natural circulation } \\
\text { Two-phase natural circulation } \\
\text { Mixture level and entrainment in the } \\
\text { core } \\
\text { Heat transfer in steam generator } \\
\text { Heat transfer in covered core } \\
\text { Heat transfer in partly uncovered core } \\
\text { Loop seal clearance }\end{array}$ & $\begin{array}{l}\text { Basic phenomena in } \\
\text { transients, need of data in } \\
\text { "clean" boundary conditions } \\
\text { (outcome of VVER } \\
\text { validation matrix). } \\
\text { Recommended by } \\
\text { Gosatomnadzor }\end{array}$ & - \\
\hline (3) & $\begin{array}{c}\text { CL- } 4.1- \\
03\end{array}$ & $\begin{array}{c}4.1 \% \text { cold leg break } \\
\text { test }\end{array}$ & $\begin{array}{l}\text { Break flow } \\
\text { Two-phase natural circulation } \\
\text { Asymmetrical loop behaviour } \\
\text { Mixture level and entrainment in the } \\
\text { core } \\
\text { ECCS mixing and condensation } \\
\text { Pool formation in the upper plenum } \\
\text { Heat transfer in the covered core } \\
\text { Heat transfer in uncovered core } \\
\text { (dryout) } \\
\text { Rewet and quenching } \\
\text { Thermal-hydraulics in pressurizer } \\
\text { Loop seal clearance }\end{array}$ & $\begin{array}{l}\text { Relevant bounding case } \\
\text { phenomenon. Data lacking, } \\
\text { as from recommendation of } \\
\text { OECD support group on the } \\
\text { VVER validation matrix. } \\
\text { Relevant for VVER safety } \\
\text { assessment. } \\
\text { Recommended by } \\
\text { Gosatomnadzor }\end{array}$ & $\begin{array}{l}\text { Counter-part of } \\
\text { LOBI, BETHSY, } \\
\text { SPES, and LSTF }\end{array}$ \\
\hline$(4)$ & $\begin{array}{c}\text { PSh-1.4- } \\
04\end{array}$ & $\begin{array}{c}\text { Primary to secondary } \\
\text { leak }\end{array}$ & $\begin{array}{l}\text { Break flow } \\
\text { Two-phase natural circulation } \\
\text { Mixture level and entrainment into SG } \\
\text { Mixture level and entrainment into the } \\
\text { core } \\
\text { ECCS mixing and condensation } \\
\text { Pool formation in the upper plenum } \\
\text { Heat transfer in the covered core } \\
\text { Heat transfer in uncovered core } \\
\text { (dryout) } \\
\text { Heat transfer in steam generator } \\
\text { Thermal-hydraulics in pressurizer } \\
\text { Loop seal clearance }\end{array}$ & $\begin{array}{l}\text { Absence of test data for } \\
\text { "primary to secondary leak" } \\
\text { (VVER validation matrix). } \\
\text { Recommended by } \\
\text { Gosatomnadzor. Highly } \\
\text { relevant for VVER safety } \\
\text { assessment from point of } \\
\text { view of radiological } \\
\text { consequence }\end{array}$ & $\begin{array}{l}\text { Analytical } \\
\text { exercise among } \\
\text { project } \\
\text { participants } \\
\text { (blind test) }\end{array}$ \\
\hline (5) & $\begin{array}{c}\text { CL- } \\
2 \times 100-01\end{array}$ & Large cold leg break & $\begin{array}{l}\text { Break flow } \\
\text { Asymmetrical loop behaviour } \\
\text { Mixture level and entrainment in the } \\
\text { core } \\
\text { ECCS mixing and condensation } \\
\text { CCFL } \\
\text { Pool formation in the upper plenum } \\
\text { Heat transfer in the covered core } \\
\text { Heat transfer in uncovered core } \\
\text { (dryout) } \\
\text { Quenching } \\
\text { Thermal-hydraulics in pressurizer } \\
\text { Loop seal clearance }\end{array}$ & $\begin{array}{l}\text { Important for safety } \\
\text { assessment evaluations, } \\
\text { strongly supported by } \\
\text { Gosatomnadzor }\end{array}$ & $\begin{array}{l}\text { Benchmark } \\
\text { among project } \\
\text { participants }\end{array}$ \\
\hline
\end{tabular}


a rupture on one upper plenum accumulator line and it is a "similar test" performed in another facility, ISBVVER, which is scaled down 1 to 2000. It was also used as shake-down test for the PSB-VVER facility, namely, to check the instrumentation and the system behavior [8]. The comparison with the data of the integral ISB-VVER facility provided feedbacks about the scaling effects on the accident behavior. The transient is initiated by an intermediate break simulating the rupture of one hydroaccumulator line located in upper plenum. The high-pressure injection system (HPIS), connected to one hot leg, is available only in one loop. The onset of the injection of hydroaccumulator systems occurs shortly before the fuel rod simulator bundle heat up starts. Then, continuous heat up and rewet of fuel rod simulators is experienced during the transient, because the stepwise intervention of the hydroaccumulators.

The second experiment is a natural circulation test [9]. The design of the experiment is aimed to obtain a set of data in natural circulation. The test consists in step wise reduction of the primary side mass inventory. Between two consecutive drainage phases, "quasi" stationary conditions are achieved in the system. These conditions are suitable to investigate main modes of operation, which might occur during a small break LOCA. In particular, the phenomena connected with the single- and two-phase natural circulation, boiler condenser mode up to the dryout occurrence are studied at various primary coolant inventories in a VVER-1000 configuration.

A small break LOCA is the third experiment [10]. It is a "counterpart test" of the experiments carried out in LOBI, SPES, BETHSY, and LSTF facilities. The experiment is a $4.1 \%$ cold leg break test aimed at providing data on the scaling criteria of the facility and its performance in comparison with the other integral test facilities simulating different pressurized water reactor designs. Starting from the past experiments, the design of the small break LOCA test has been a collaboration between EREC and University of Pisa. The boundary and initial conditions, and the imposed sequence of events have been defined on the basis of welldefined scaling laws in order to carry out a correct "counterpart test" [11]. Focus is also given on the identification and verification of the thermal hydraulic phenomena, according with the validation matrices for transients [1-3]. Similarities and differences of the processes/phenomena running in the PSB-VVER and LOBI test facilities have been also analyzed.

The fourth experiment of the test matrix is related to the primary-to-secondary leak issue [12]. The initiating event is the opening of the steam generator header lid with an equivalent break size of about $100 \mathrm{~mm}$, that is, an intermediate break. This scenario is relevant for VVER safety analysis, because it occurred in Rovno nuclear power plant. In this scenario, the primary liquid can be released into the containment through the steam generator relief valves and, without actions of the operator, might be the cause of core degradation. The experiment is executed accounting also for the single failure. It consists in the occurrence of the relief valve stuck open in the affected steam generator. This test is selected by the OECD/NEA PSB-VVER project participants as one for analytical exercise (blind test). Five countries with six codes participated to the blind test, and four countries with five codes performed the posttest calculations [13].

The last test is a large cold leg break LOCA. The test is a double-ended guillotine break in cold leg, between pump and pressure vessel, downstream of the emergency core cooling injection to be performed at "full power" [14]. This corresponds to $10 \mathrm{MW}$ in PSB-VVER integral test facility (ITF) that is scaled one to three hundred. Nevertheless, the fuel core is simulated with indirect electric heated cans, which are not able to withstand to such power. Therefore, the test is performed at "low" power $(1.5 \mathrm{MW})$ and has been used for a benchmark activity, hereafter described [15].

\section{The Experiment}

3.1. PSB-VVER Facility Description. PSB-VVER is an integral test facility [7] simulating the Russian-designed pressurized light water reactor VVER-1000 v320 (see Figure 1). It is installed at the Electrogorsk Research and Engineering Centre, near Moscow (Russia). The role of such integral test facility in accident analysis, within the nuclear reactor safety technology framework, is primarily to confirm the predictive capabilities of thermal-hydraulic system codes and to trigger the process of code improvement, if needed. The PSB-VVER is characterized by the "time-preserving," "full-pressure," "full-height," "full-linear-heat-generation-rate," and "powerto-volume" scaling laws, such as other experimental facilities (i.e., PKL, LOBI, SPES, BETHSY, LSTF, PMK, SEMISCALE, and LOFT). It is designed and constructed with the following purposes:

(i) obtain experimental data for studying phenomena and processes specified in the validation matrices developed for VVER nuclear power plants,

(ii) assess the efficiency of the existing safety systems and verify engineering approaches proposed in new VVER nuclear power plants designs,

(iii) check and evaluate the existing accident management recommendations and procedures,

(iv) expand the experimental database used for thermalhydraulic code validation for VVERs.

The PSB-VVER facility is scaled down 1 to 300 . It models the entire primary system and most of the secondary system (except turbine and condenser). The facility allows the modeling and representation of phenomena and physical phases that are relevant to VVER-1000 reactor under transient and emergency conditions and to investigate the regimes in accordance with accident management. It is equipped with a data acquisition system that includes more than 1000 measuring channels with a sampling frequency up to $100 \mathrm{~Hz}$. The complete description of the PSB-VVER facility can be found in $[7,16,17]$. The scaling concepts fulfill the requirements needed to simulate the overall 


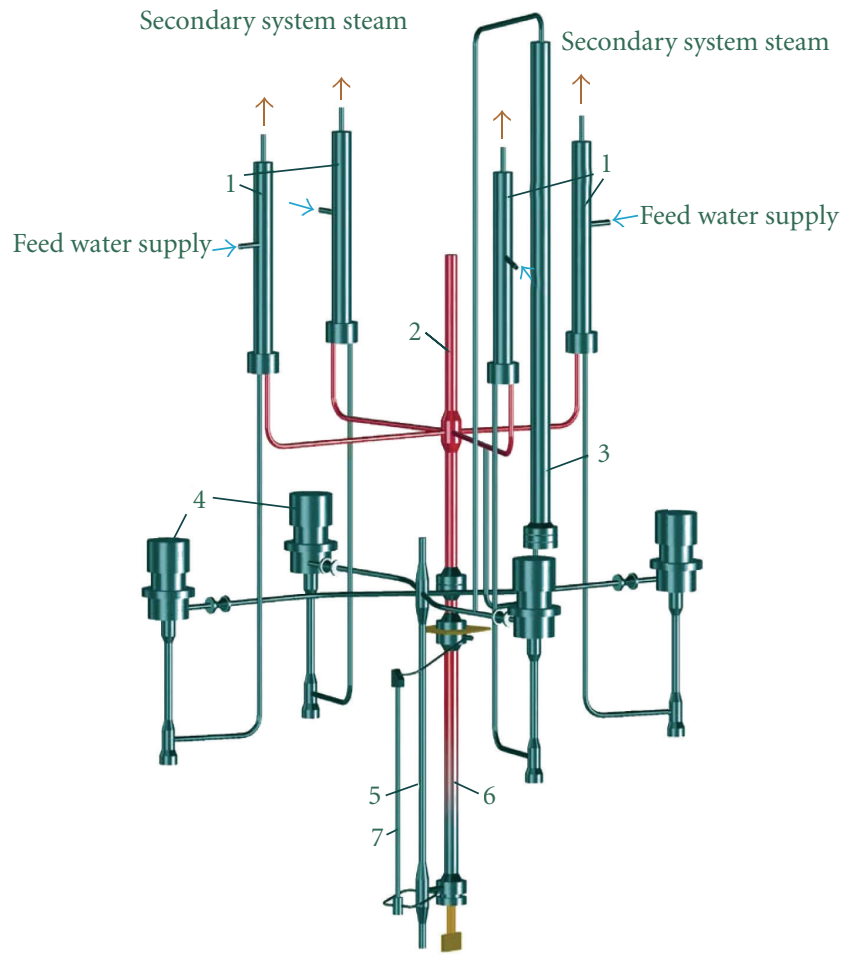

(a) General view of the facility

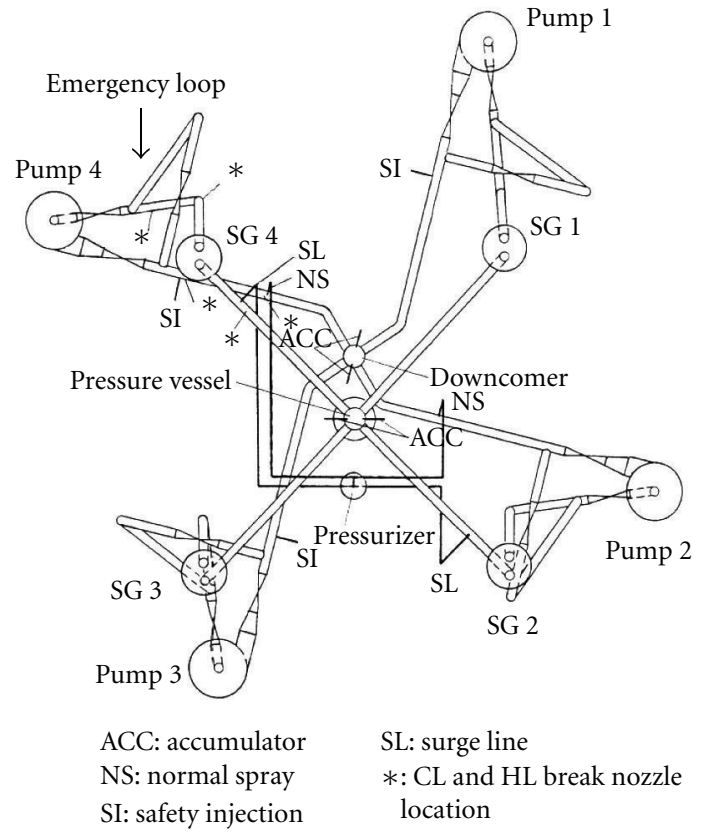

(b) Primary system top view

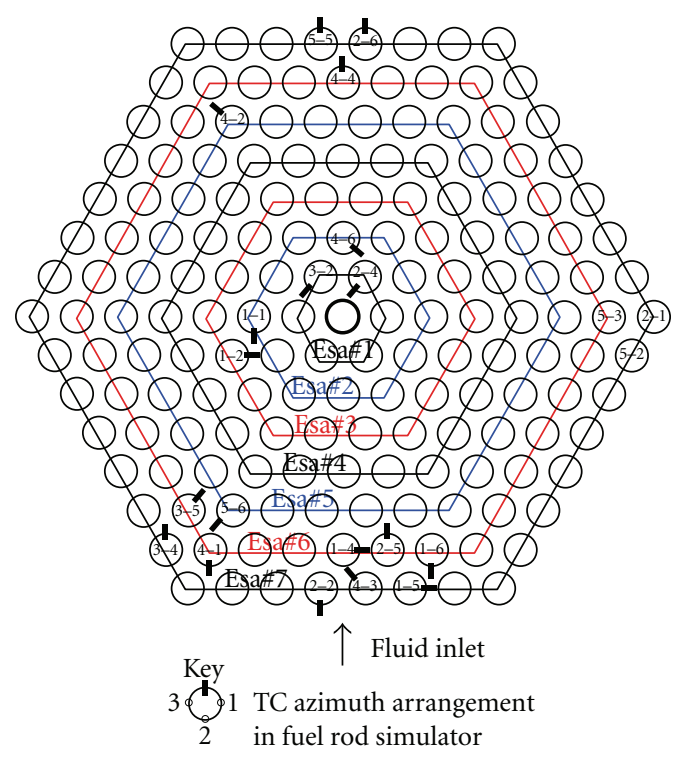

(c) Arrangement of the thermocouples in the FRSB

FIGURE 1: PSB-VVER facility installed at EREC (Russia).

thermal-hydraulics behavior of the full-scale power plant. Relevant features are hereafter listed:

(i) facility elements scaled in elevation $1: 1$;

(ii) power, volume, and cross-sectional area scaling factor of $1: 300$; (iii) full pressure of the primary and secondary systems;

(iv) simulation of all four loops;

(v) fuel rod and horizontal SG tubes scaled in length $1: 1$. 
3.2. Test 5 a "CL-2x100-01" Description. The main objectives of the test $5 \mathrm{a}$, identified as "CL-2x100-01", are as follows [14, $18]$ :

(i) to obtain experimental data not covered by the VVER validation matrix,

(ii) to investigate the thermal-hydraulic response of the VVER-1000 primary system during a double-ended guillotine break in cold leg;

(iii) to obtain experimental data for validation of thermalhydraulic system codes applied to LB-LOCA analysis of VVER-1000;

(iv) to evaluate the capability of the PSB-VVER facility to simulate the LB-LOCA in VVER-1000.

The experiment starts with the ruptures of the membranes in cold leg number 3 and the closure of the valve located between the two break devices, simulating the occurrence of the double-ended guillotine break in the facility. Six phenomenological windows are distinguished in the experiment, which are hereafter outlined.

(1) Blowdown Phase: from the start of the transient (SoT) up to reactor pressure vessel level increase. Once the break (double ended) is opened, the loss of offsite alternating current (AC) power is assumed simultaneously. This implies the following events: SCRAM occurrence, the onset of the main coolant pumps coastdown, the turbine valve, and the main feed water pumps closures. The loss of offsite AC power causes the inhibition of the active emergency core cooling system, up to $40 \mathrm{~s}$ (availability of the diesel generators). The primary pressure decreases fast (Figure 2), therefore the primary side coolant evaporates. Condition for critical heat flux occurs in the core. However, no dryout is observed in the experimental data due to the SCRAM at time $0 \mathrm{~s}$ and the low energy stored in the fuel. The accumulators start to inject in upper plenum and downcomer at about $10 \mathrm{~s}$. At the end of this phase, the measured reactor pressure vessel collapsed level reaches a minimum.

(2) Refill Phase: up to the accumulators effectiveness ends. The refilling of the lower plenum is driven by the accumulators' injections and later on, $40 \mathrm{~s}$ after the SoT, by the ECCS injection. During this phase a pool formation in upper plenum is observed and lasts until the end of this phase. The phase ends when the accumulators' injections are less effective, because they are almost empty.

(3) Primary Side Mass Inventory Reduction Phase: up to the onset of core heatup. During this phase the reactor pressure vessel level decreases again because the accumulators are empty. The loop seals in the intact loops are completely emptied. The downcomer level increases at the beginning of the phase and then, oscillates at the end of the phase before the dryout phase starts (Figure 3).

(4) Dryout Phase: up to core quenching. The phase is characterized by the temperatures excursions in the fuel rod simulator bundle. During this phase, the primary system mass inventory slightly increases, because the positive mismatch between the active ECCS and the mass released through the break.

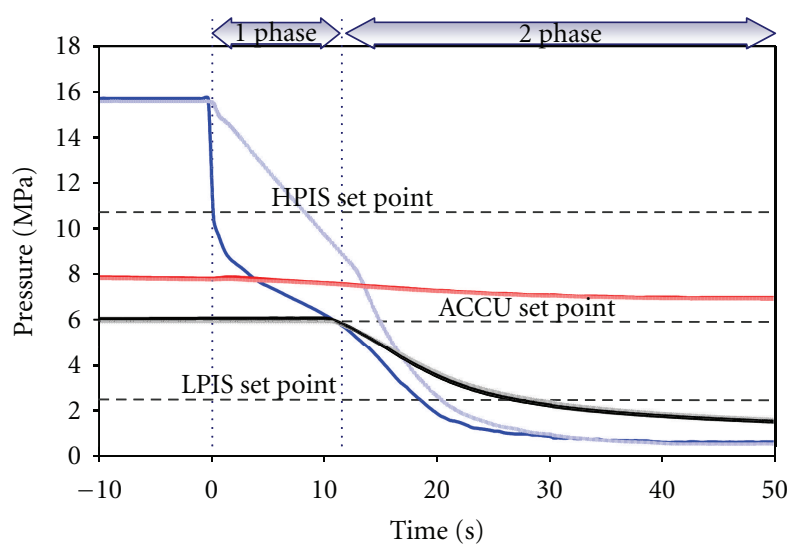

(a) Zoom from $-10 \mathrm{~s}$ to $50 \mathrm{~s}$

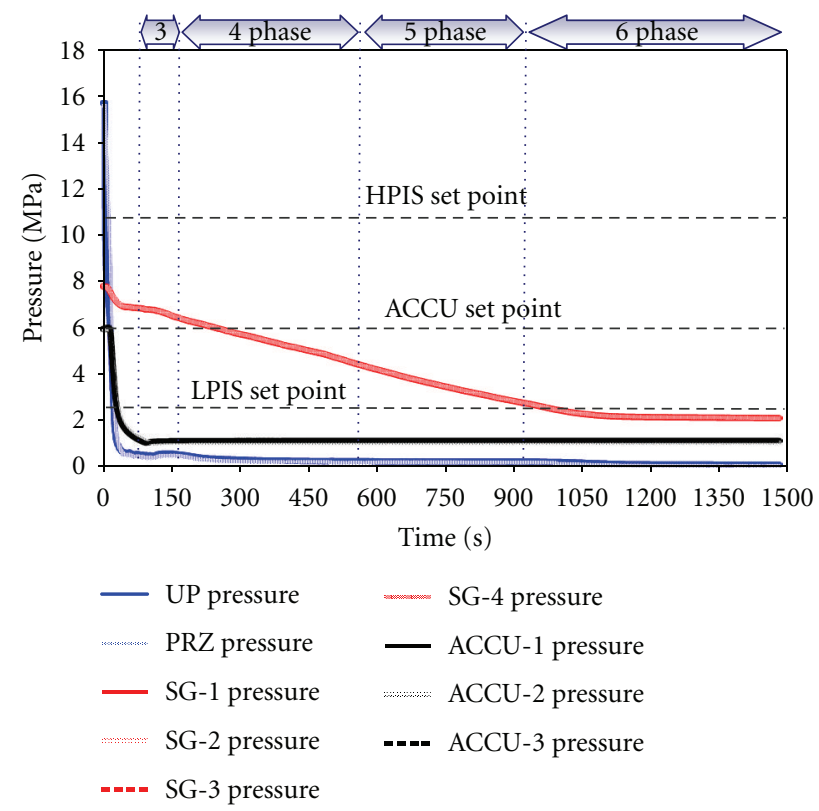

(b) Overall transient

FIGURE 2: OECD/NEA experiment PSB-VVER CL-2x100-01: measured trends of upper plenum (YC01P16), pressurizer (YP01P01) steam generators (YB01-04P01), and accumulators pressures (TH01-04P01).

(5) Stable Safe Condition Phase: up to the active ECCS tanks emptying. This is a transition phase, since the safe conditions are achieved. The primary mass inventory continuously increases as well as the collapsed level in the riserside of the reactor pressure vessel. Once the active ECCS have injected $1.86 \mathrm{~m}^{3}$ of water, according to the scenario specifications, the LPIS and HPIS pumps are switched off.

(6) Primary Side Mass Inventory Depletion Phase and End of Transient (EoT): the last phase is characterized by a slow empting of the primary system until the final dryout occurs. The test ends at $1477 \mathrm{~s}$ when the maximum core temperature measured reaches about $515^{\circ} \mathrm{C}$.

The complete description of the test is available in the experimental data report, issued by EREC [18]. 


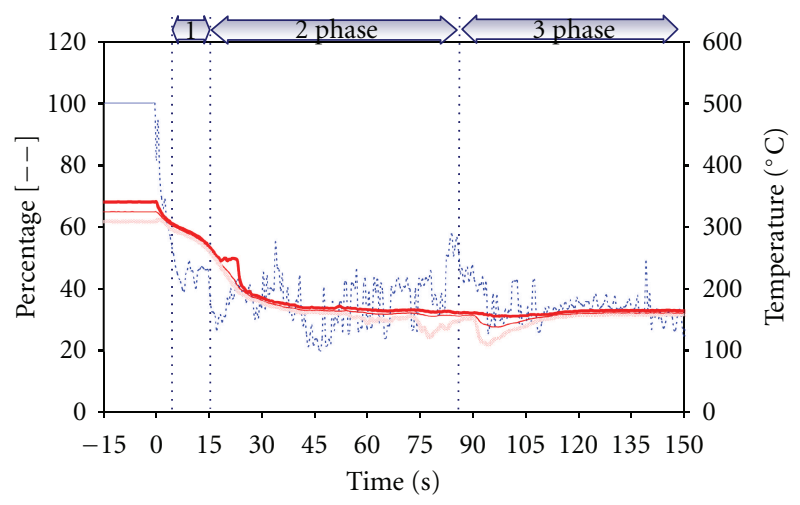

(a) Zoom from $-15 \mathrm{~s}$ to $150 \mathrm{~s}$

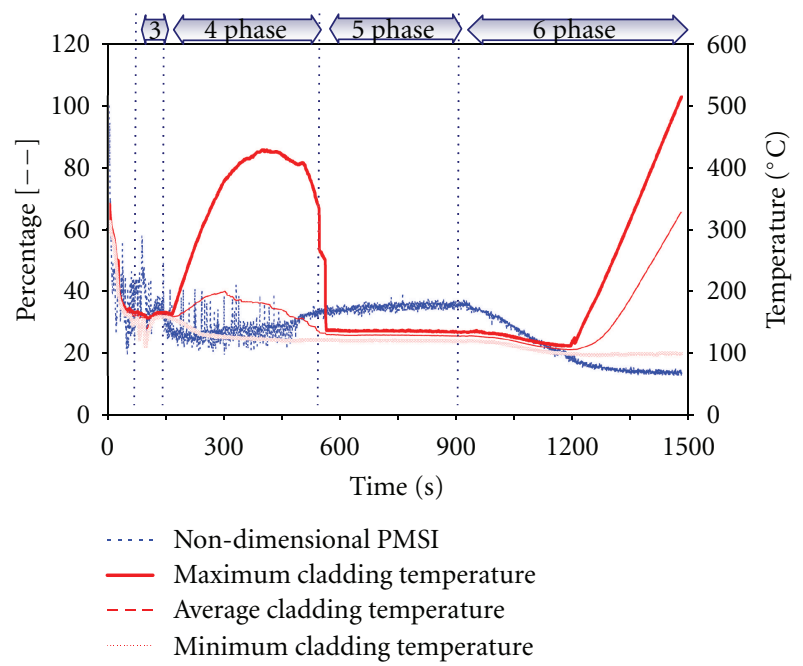

(b) Overall transient

Figure 3: OECD/NEA experiment PSB-VVER CL-2x100-01: nondimensional trend of primary side mass inventory (PMSI); upper and lower envelops and average value of all cladding temperatures measurements.

\section{Benchmark on LB-LOCA Transient in PSB-VVER Facility}

4.1. Objectives of the Activity. The OECD/NEA PSB-VVER Test 5a benchmark [15] is focused on the assessment of Western and Eastern thermal-hydraulic system codes in predicting large break LOCA phenomena occurring in VVER-1000 prototype reactor. The main objectives of the benchmark are as follows:

(i) to assess the current capabilities of the thermalhydraulic system codes on the domains of interest,

(ii) to develop a common understanding and to promote an exchange of knowledge,

(iii) to draw conclusions on the possible use of the codes for regulatory bodies and the industry.

4.2. Procedure for Code Assessment. The assessment of a thermal-hydraulic system code involves the availability of a qualified nodalization and of qualified experimental data from a qualified experimental facility. It also requires standard procedures and the fulfillment of specific criteria. In this context, references have been provided by University of Pisa to define the meaning of "qualified nodalization," to develop the procedure and the criteria necessary for preparing a "qualified nodalization," to perform the assessment activities, and, finally, to execute qualified computer code calculations.

The procedure for code assessment consists of three main steps, see also [19-21].

(1) The steady state results (i.e., "steady state qualification"), which may include the nodalization development phase (e.g., volume, heat transfer area, elevations, pressure drops distribution, etc.). This step is concluded with the simulation of the nominal steady state conditions against specific acceptability thresholds.

(2) The reference calculation results (i.e., "on transient qualification") that shall satisfy qualitative and quantitative accuracy-related criteria. According with this procedure, the reference calculation is not "the best" calculation achievable by the code.

(3) The results from sensitivity study (which is also part of the "on transient qualification") is carried out to demonstrate the robustness of the code calculations, to characterize the reasons for possible discrepancies between measured and calculated trends, to optimize code results and user options choices, and to improve the knowledge of the code by the user.

The comparative analysis, described in the following sections, is carried out on the basis of the steps 1 and 2 above.

4.3. Comparison among Participants Input Decks. The simulation of test $5 \mathrm{a}$ has been performed by four participants belonging to three different institutions with four different thermal-hydraulic system codes [15]. Gidropress (EDO-GP) submitted both pretest and posttest calculations. In details:

(1) KORSAR-GP V9.027.004, pretest, and V9.031.000, posttest (Gidropress-Russia),

(2) TECH-M (Gidropress-Russia),

(3) ATHLET 2.1 Cycle A (Nuclear Research Institute ŘežCzech Republic);

(4) RELAP5-3DV2.4.2 (University of Pisa-Italy).

Table 2 provides information regarding the adopted code resources, the nodalization features, and the main code options.

4.4. Comparison and Evaluation of Steady State Results. The steady state results have been analyzed and compared. The procedure involves two main tasks, which are as follows:

(i) the verification and evaluation of the geometrical fidelity of the model developed, also called the "nodalization development phase,"

(ii) the capability of the analytical model to achieve stable steady state with the correct initial conditions. 
TABLE 2: Information on nodalizations and the code options.

\begin{tabular}{|c|c|c|c|c|c|c|c|c|}
\hline Number & Quantity & Unit & $\begin{array}{c}\text { EDO-GP } \\
\text { pretest } \\
\text { KORSAR }\end{array}$ & $\begin{array}{c}\text { EDO-GP } \\
\text { posttest } \\
\text { KORSAR }\end{array}$ & $\begin{array}{l}\text { EDO-GP } \\
\text { pretest } \\
\text { TECH-M }\end{array}$ & $\begin{array}{l}\text { EDO-GP } \\
\text { posttest } \\
\text { TECH-M }\end{array}$ & $\begin{array}{c}\text { NRI } \\
\text { posttest } \\
\text { ATHLET }\end{array}$ & $\begin{array}{l}\text { UNIPI } \\
\text { posttest } \\
\text { R5-3D }\end{array}$ \\
\hline 1 & \multicolumn{8}{|c|}{ Adopted code resources } \\
\hline 1.1 & $\begin{array}{l}\text { Tot. no. of hydraulic } \\
\text { components primary } \\
\text { system }\end{array}$ & - & - & - & - & - & 142 & 482 \\
\hline 1.2 & $\begin{array}{l}\text { Tot. no. of hydraulic } \\
\text { components }\end{array}$ & - & 185 & 193 & - & - & 164 & 620 \\
\hline 1.3 & $\begin{array}{l}\text { Tot. no. of hydraulic } \\
\text { nodes (meshes) primary } \\
\text { system }\end{array}$ & - & - & - & $76+36$ & $76+36$ & 693 & - \\
\hline 1.4 & $\begin{array}{l}\text { Tot. no. of hydraulic } \\
\text { nodes (meshes) }\end{array}$ & - & 858 & 825 & $81+36$ & $81+36$ & 820 & 2474 \\
\hline 1.5 & $\begin{array}{l}\text { Tot. no. of heat } \\
\text { structures }\end{array}$ & - & 52 & 65 & $81+36$ & $81+36$ & 90 & 2171 \\
\hline 1.6 & $\begin{array}{l}\text { Tot. no. of mesh points } \\
\text { in the heat structures }\end{array}$ & - & 509 & 629 & 4 & 4 & 2108 & 11263 \\
\hline 1.7 & $\begin{array}{l}\text { Tot. no. of core active } \\
\text { structures }\end{array}$ & - & 10 & 10 & 30 & 30 & 20 & 20 \\
\hline 1.8 & $\begin{array}{l}\text { Tot. no. of core radial } \\
\text { meshes in the active } \\
\text { structures }\end{array}$ & - & - & - & 7 & 7 & 3 & 13 \\
\hline 2 & \multicolumn{8}{|c|}{ Nodalization features } \\
\hline 2.1 & No. of modeled loops & - & 4 & 4 & 4 & 4 & 4 & 4 \\
\hline 2.2 & $\begin{array}{l}\text { No. of horizontal tubes } \\
\text { per SG }\end{array}$ & - & 4 & 4 & 1 & 1 & 5 & 17 \\
\hline 2.3 & Core model (3D or 1D) & - & $1 \mathrm{D}$ & $1 \mathrm{D}$ & $1 \mathrm{D}$ & $1 \mathrm{D}$ & $1 \mathrm{D}$ & $1 \mathrm{D}$ \\
\hline 2.4 & $\begin{array}{l}\text { No. of hydraulic } \\
\text { channels in core region }\end{array}$ & - & 1 & 1 & 3 & 3 & 2 & 2 \\
\hline 2.5 & $\begin{array}{l}\text { Cross-flow junctions } \\
\text { between parallel } \\
\text { channels in the core }\end{array}$ & - & Yes & Yes & No & No & No & Yes \\
\hline 3 & \multicolumn{8}{|c|}{ Code options } \\
\hline 3.1 & $\begin{array}{l}\text { Reflood model } \\
\text { top-down }\end{array}$ & - & - & Yes & Yes & Yes & No & Yes \\
\hline 3.2 & $\begin{array}{l}\text { Reflood model } \\
\text { bottom-up }\end{array}$ & - & - & Yes & Yes & Yes & No & Yes \\
\hline 3.3 & CCFL model & - & - & No & Yes & Yes & Wallis & No \\
\hline
\end{tabular}

Although the first task is outside of the scope of the activity, the participants provided relevant geometrical data with the objective to allow a more comprehensive understanding of the differences among the results of the codes [15].

The achievement of the steady state conditions (task two) deals with the comparisons between the experimental measurements and the calculated results at the start of transient (SoT). The selection of the key parameters for steady state verification is done taking into account the availability of the experimental data. Anyway, some parameters are compared, even though they are not available in the experimental database (i.e., steam generators power exchanged, maximum fuel centerline temperature, accumulators mass inventory, steam generators mass inventory, core and, upper headdowncomer bypass flow rates). No error is considered if the calculated value is inside the bands of the measurement accuracy. If it is outside, the error is calculated as difference between the calculated value and upper or lower limit of the measured value.

Figure 4 shows the verification of the pressure drops in the reactor pressure vessel and in the reactor coolant system. The verification of the pressure drop across the vessel reports two different set of experimental data: one (reported with the blue dashed line label "YC01DP16b" in Figure 4(a)) is the direct measure from inlet to outlet of the pressure drop and the second (black line) is calculated through the chain of the pressure drops measurements available in the reactor pressure vessel. Almost all calculated values are inside or close the experimental value $(19.80 \mathrm{kPa})$ considering the measurement uncertainty $( \pm 1.5 \mathrm{kPa})$. On the other side the 


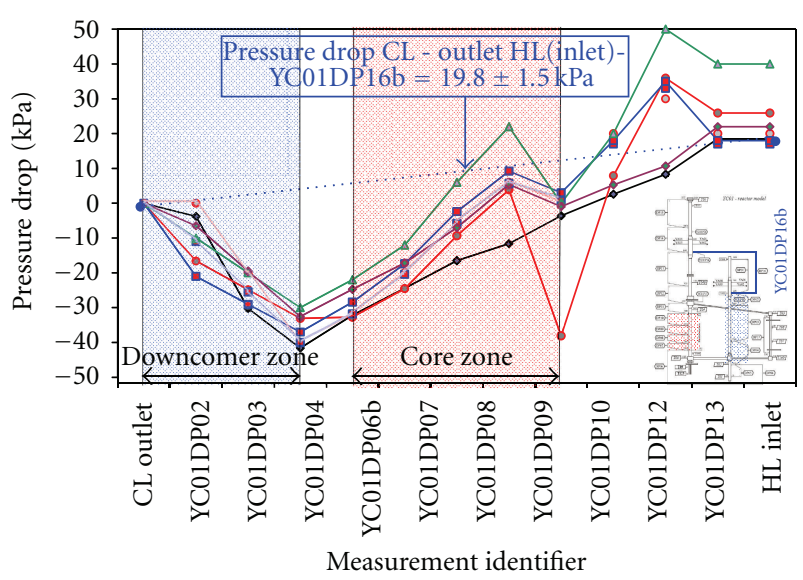

(a) RPV pressure drop versus length

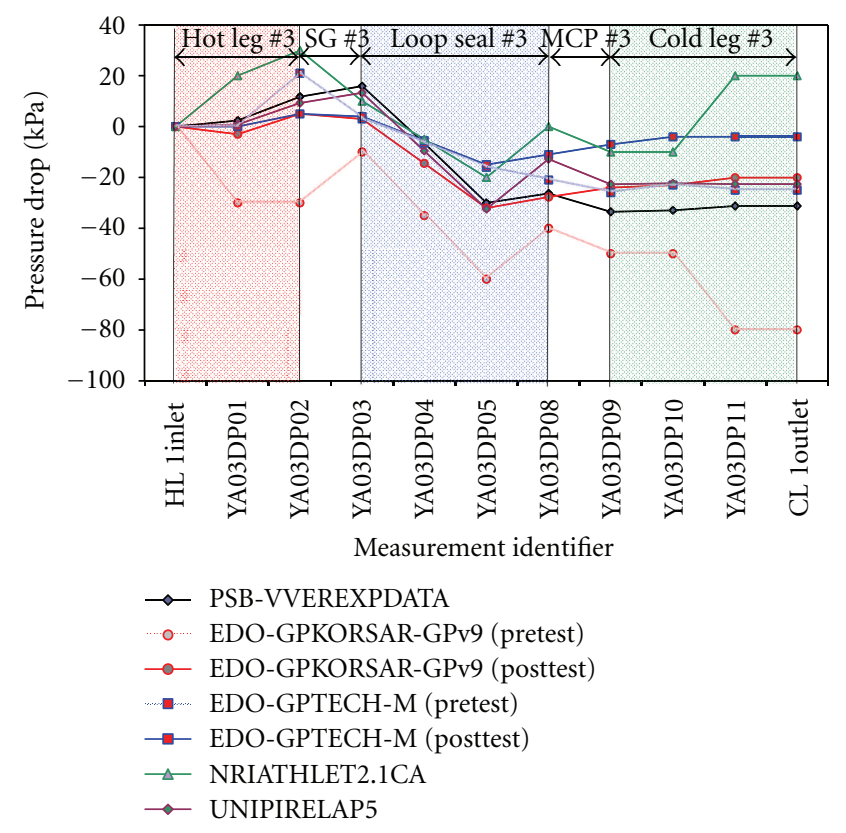

(b) Loop no. 3 pressure drop versus length

FIGURE 4: Primary system pressure drop versus length.

verification of the pressure drop in the loop seal number 3 shows larger discrepancy between the calculated values and the measurement trend. These differences can be attributed to the propagation of the errors connected with the chain of measured pressure drops used. Indeed, the final absolute value should be equal to the pressure drop across the reactor pressure vessel. The analysis [15], not detailed in the present paper, demonstrated that the codes results are in general acceptable, even though some errors exceed the acceptability thresholds [19].

4.5. Comparison and Evaluation of Reference Results. The analysis of the results is based on a comprehensive comparison between measured and calculated trends and values, aimed at demonstrating that the codes simulations are capable to reproduce the relevant thermal-hydraulic phenomena observed in the experiment. This is performed in four relevant checks.

The first check consists in comparing the values of quantities characterizing the sequence of events, and is part of the qualitative evaluation of the results (see Section 4.2 no. (2)). Table 3 reports the list of the relevant events and the timing of their occurrences.

The second check (qualitative evaluation) is the comparisons between experimental and calculated time trends on the basis of selected variables. The complete set of time trends used for the analysis is based on 55 parameters [15]. Among those parameters, 18 are selected for the quantification of the accuracy by the application of the FFTBM (check four, below). These represent the minimum number of quantities describing the experimental scenario and the code performances. The description of the parameter trends is provided by grouping the homogeneous quantities: that is, absolute pressures, coolant temperatures, mass flow rates, integral mass, pressure drops, levels, cladding temperatures, and powers. As sample, the time trends of the upper plenum pressures and of the maximum cladding temperatures provided by the participants are compared in Figure 5 .

The primary pressure trend is well simulated by the codes, with the exception of a pretest calculation. The cladding temperatures reported in Figure 5(b) represent the code predictions at the height, where the experimental measure experiences the maximum cladding temperature (2.8-3.2 $\mathrm{m}$ from bottom of active fuel). The figure shows the first dryout occurrence and the maximum PCT well simulated by RELAP 5 and the final core heat up by ATHLET. It should be noted that the maximum cladding temperature by ATHLET code is predicted at higher elevation and it is close to the experimental value $\left(398^{\circ} \mathrm{C}\right.$ instead of $428^{\circ} \mathrm{C}$ measured in the experiment), see [15].

The third check is the qualitative accuracy evaluation of the results on the basis of the relevant thermal-hydraulic aspects. These are derived from the analysis of the transient, its subdivision in phenomenological windows, and then the identification of the relevant phenomena following a rigorous approach [20].

The transient has been divided in 8 different RTA. They are break flow rate behavior, PRZ behaviour, first dryout occurrence, UP pressure behavior, accumulator behavior, ECCS (HPIS and LPIS) behavior, primary side mass behavior, and final dryout occurrence. Each RTA has been characterized by several quantities, which are used for evaluating the accuracy of the code simulations: that is, time sequence of event (TSE), integral parameter (IP), single value parameter (SVP), and nondimensional parameter (NDP). For each of these quantities an engineering judgment is provided according with the following criteria:

(a) "E" mark: the code predicts qualitatively and quantitatively the parameter (excellent-the calculation result is within experimental data uncertainty band);

(b) " $R$ " mark: the code predicts qualitatively, but not quantitatively the parameter (reasonable-the calculation result shows only correct behavior and trends); 
TABLE 3: Resulting sequence of main events.

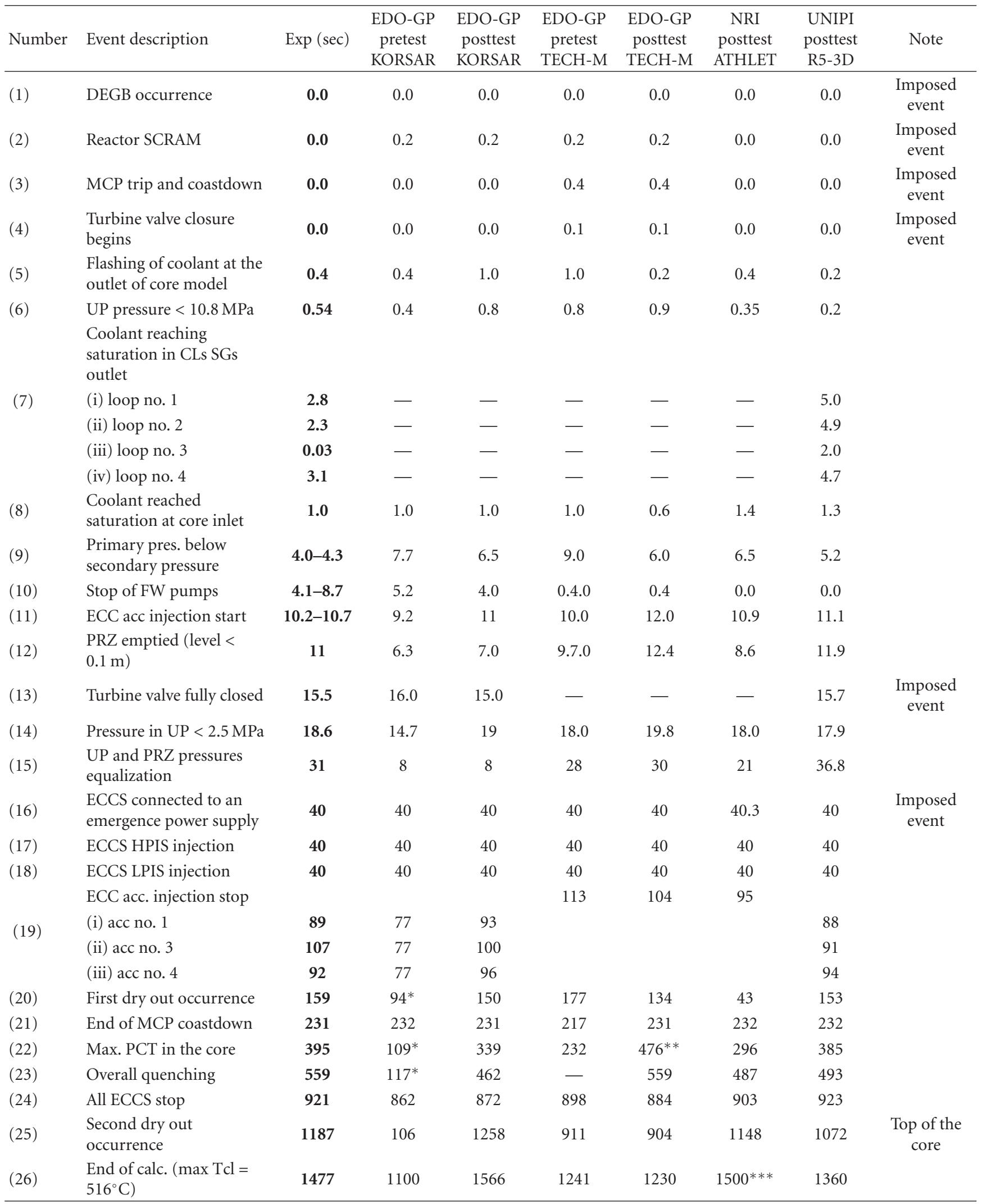

(*) First out of 5 dryout experienced at different axial levels, especially in the lower part of the core. $(* *)$ Second out of two dryout.

$(* * *)$ Corresponding to a maximum cladding temperature equal to $500^{\circ} \mathrm{C}$. 


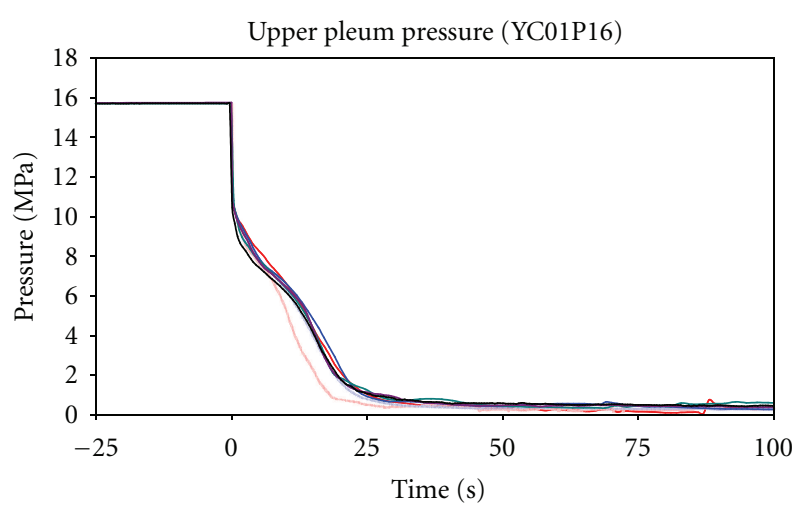

(a) UP pressure trends (zoom from $-25 \mathrm{~s}$ to $100 \mathrm{~s}$ )

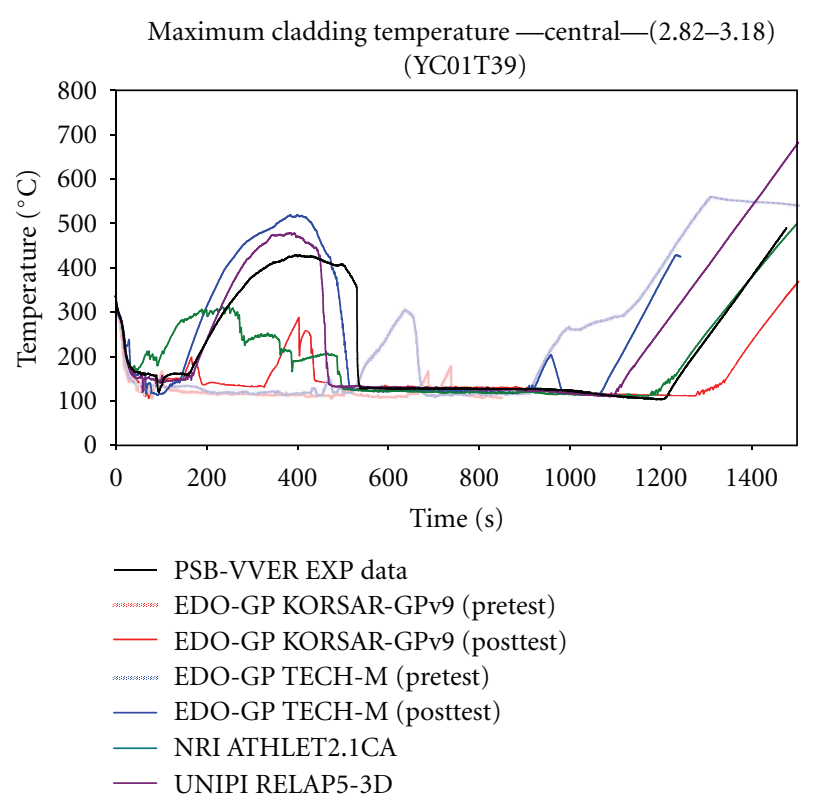

(b) Maximum cladding temperature trends in central zone between 2.82 and $3.18 \mathrm{~m}$

FIGURE 5: Qualitative evaluation of the results: experimental versus calculated time trends.

(c) "M" mark: the code does not predict the parameter, but the reason is understood and predictable (minimal - the calculation result lies within experimental data uncertainty band and sometimes does not have correct trends);

(d) "U" mark: the code does not predict the parameter and the reason is not understood (unqualifiedcalculation result does not show correct trend and behavior, reasons are unknown and unpredictable).

A positive overall qualitative judgment is achieved if " $U$ " mark is not present. The qualitative accuracy evaluation supports the conclusion that the posttest calculations are qualitatively correct. Details of the results are not reported for sake of brevity and are available in [15].
The fourth check is the quantitative accuracy evaluation by using the fast fourier transform-based method (more details in [21]). This tool, developed at University of Pisa, is applied once the other checks, previously discussed, are positively fulfilled and the code results are judged satisfactory from the qualitative point of view. This tool provides an error function, which satisfies the following requirements:

(i) at any time of the transient this function should remember the previous history,

(ii) engineering judgment should be avoided or reduced,

(iii) the mathematical formulation should be simple,

(iv) the function should be nondimensional,

(v) it should be independent from the transient duration,

(vi) compensating errors should be taken into account (or pointed out),

(vii) its values should be normalized.

The FFTBM is used for the quantification of the accuracy of the code results. This tool gives an accuracy coefficient (AA) and a weighted frequency (WF) for each variable and for the overall transient. The most significant information given by AA is the relative magnitude of the discrepancy coming from the comparison between the calculation and the corresponding experimental variable time history. When the calculated and the experimental data are equal, then the error function is zero (AA is also equal to zero), characterizing perfect agreement. The WF factor characterizes the kind of error, because its value emphasizes where the error has more relevance either at low or high frequencies. For instance, oscillations of the calculated values around an average trend can be readily identified by the method. Depending on the transient, high-frequency errors may be more acceptable than low (in thermal-hydraulic transient, better accuracy is generally represented by low AA values at high WF values), see also [22, 23].

The method was applied on the basis of 18 parameters (see Figure 6). They were selected as the minimum number relevant to describe the transient (see also step 2), considering the peculiarities of the transient, as well as the quality and availability of the experimental data. Then, those parameters are combined to give an overall picture of the accuracy of a given calculation ( $\mathrm{AA}_{\text {tot }}$ in Figures 6 and 7). The total average amplitude of the transient $\left(\mathrm{AA}_{\text {tot }}\right)$ is the result of the sum of all the average amplitudes with their "weights." The "weight" of each contribution is dependent on the experimental accuracy, the relevance of the addressed parameter, and a component of normalization with reference to the average amplitude evaluated for the primary side pressure (more details in $[20,24]$ ). The reference results of 


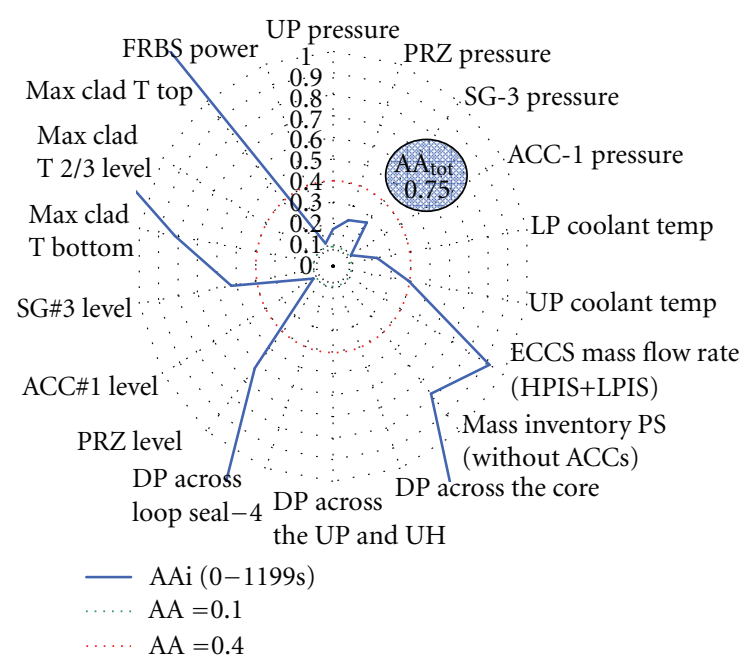

(a) KORSAR pretest (zoom from $\mathrm{AAi}=0$ and $\mathrm{AAi}=1.0$ )

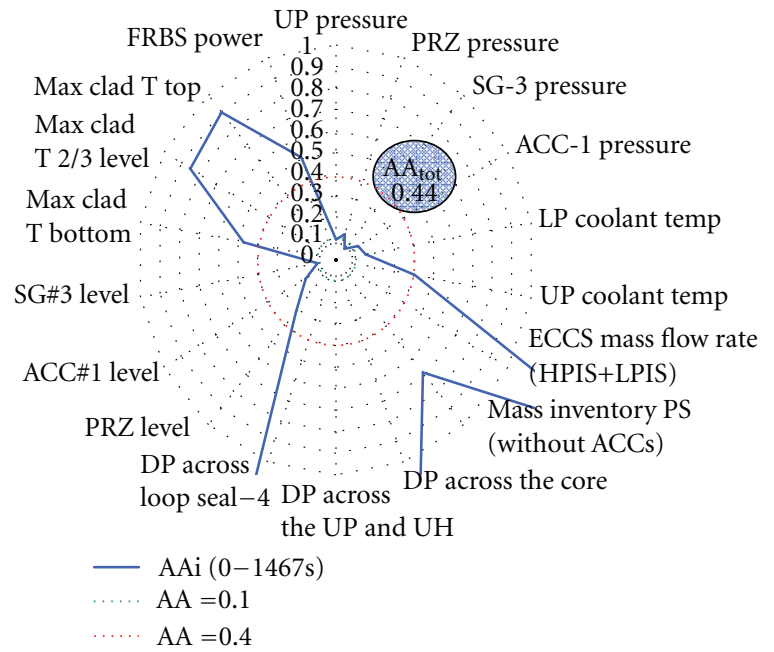

(c) $\mathrm{TECH}-\mathrm{M}$ pretest $($ zoom from $\mathrm{AAi}=0$ and $\mathrm{AAi}=1.0)$

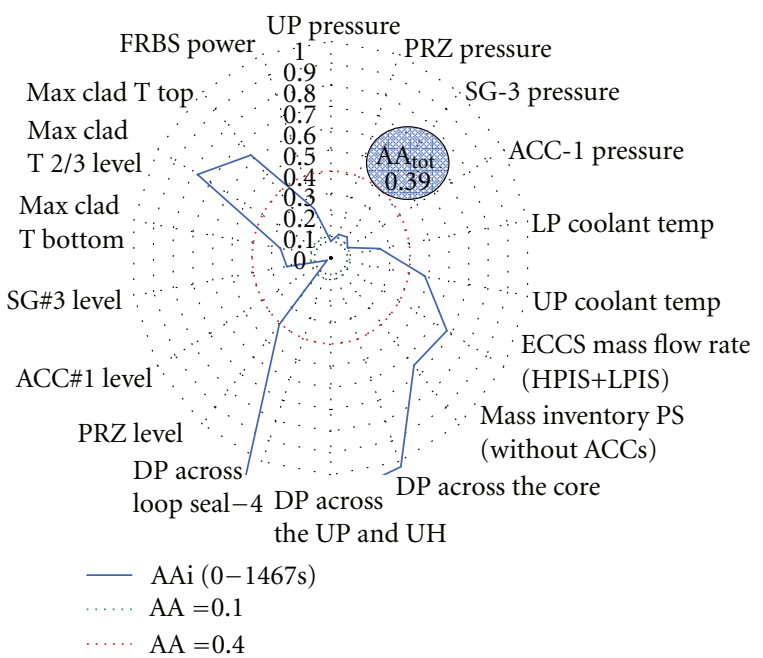

(e) ATHLET posttest (zoom from $\mathrm{AAi}=0$ and $\mathrm{AAi}=1.0)$

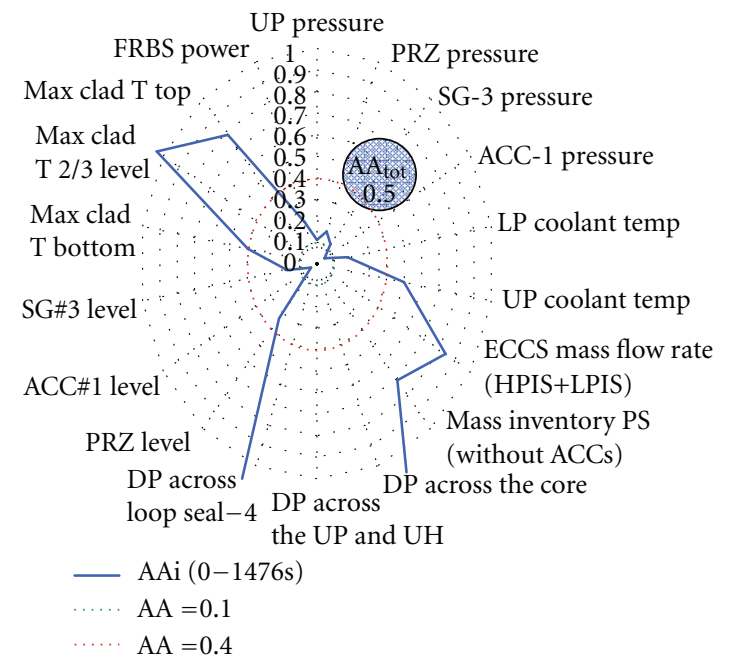

(b) KORSAR posttest (zoom from $\mathrm{AAi}=0$ and $\mathrm{AAi}=1.0$ )

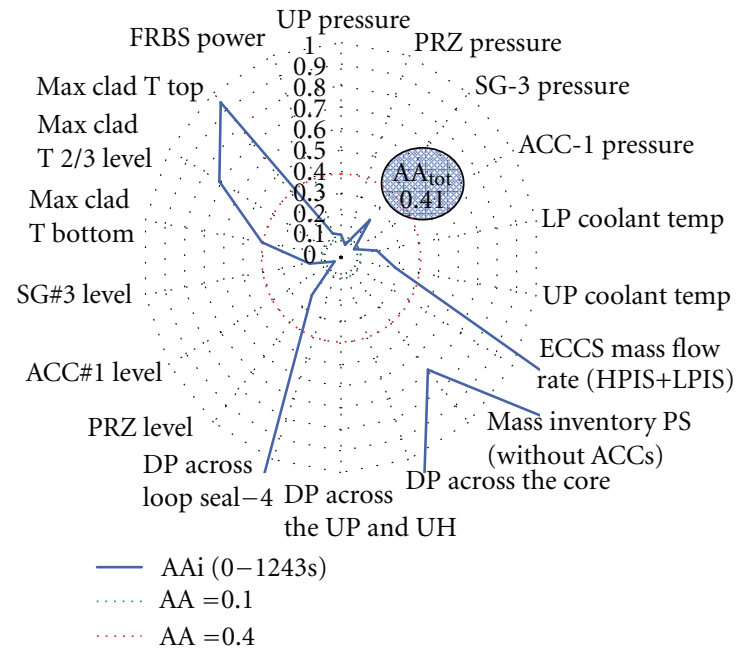

(d) $\mathrm{TECH}-\mathrm{M}$ posttest $($ zoom from $\mathrm{AAi}=0$ and $\mathrm{AAi}=1.0)$

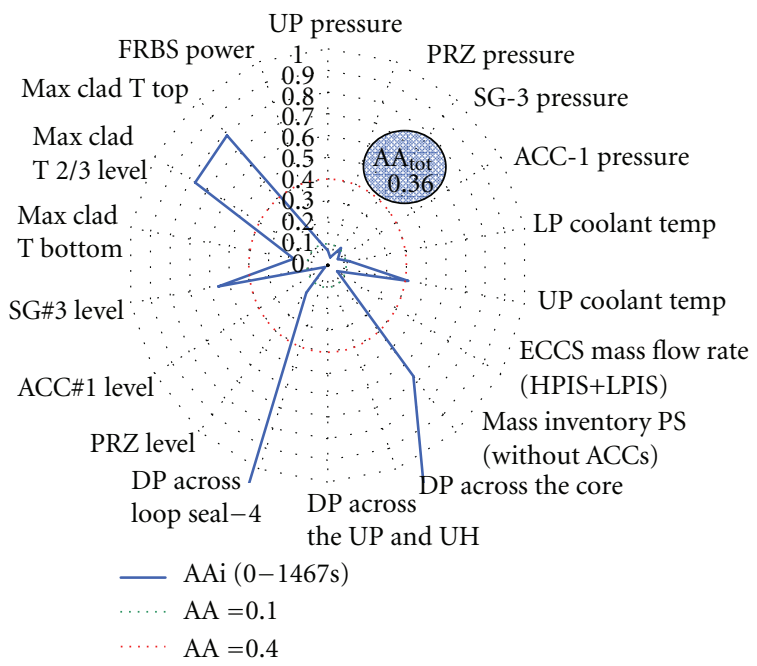

(f) RELAP5-3D posttest (zoom from $\mathrm{AAi}=0$ and $\mathrm{AAi}=1.0$ )

FIGURE 6: FFTBM application: quantitative accuracy evaluation of the results (overall transient). 


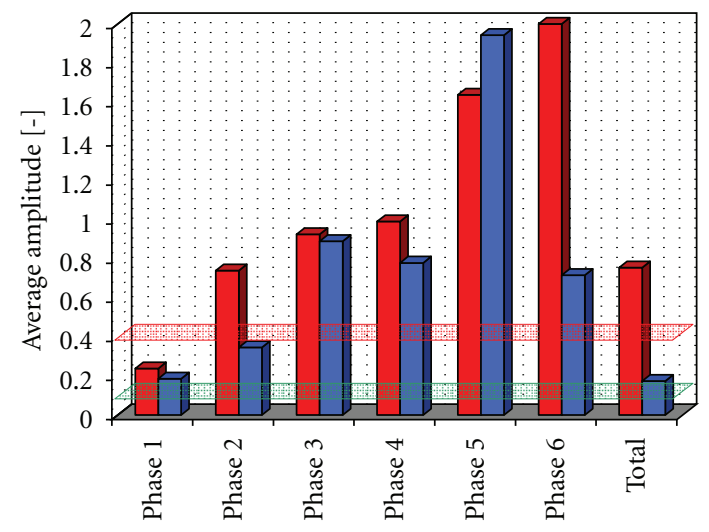

(a) KORSAR pretest

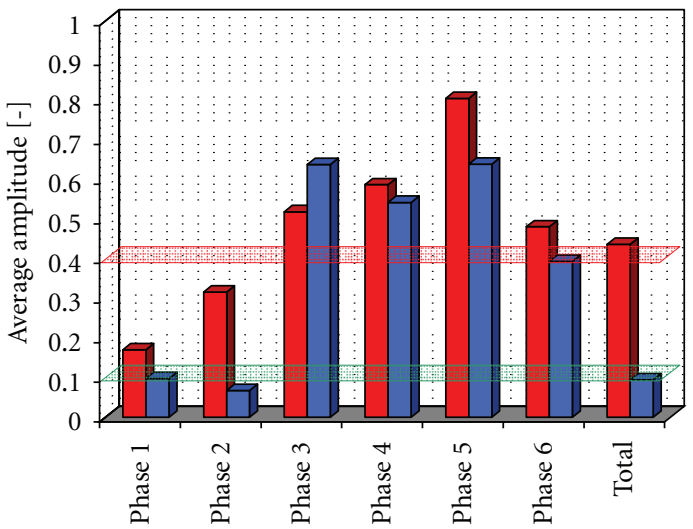

(c) TECH-M pretest

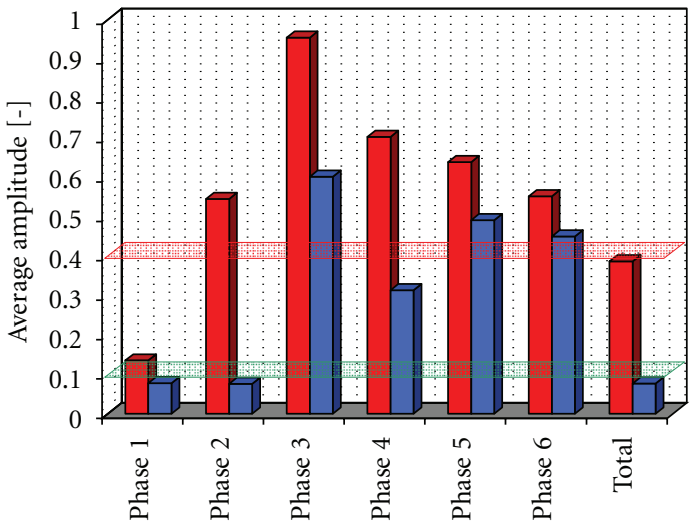

口 AAtot

口 AAp

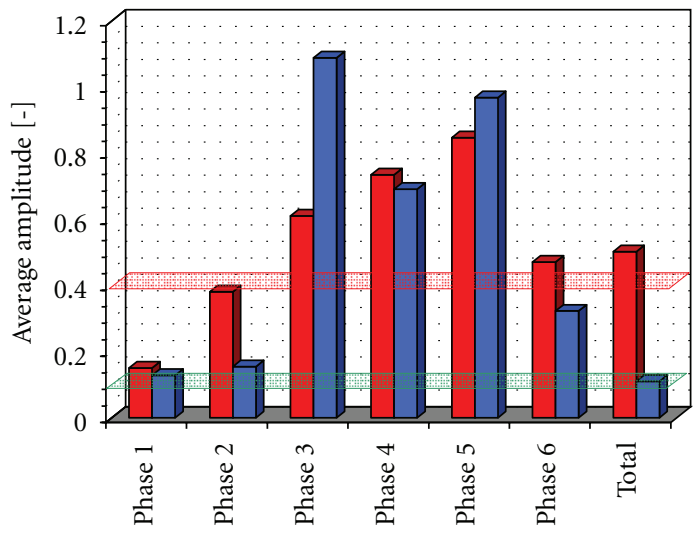

(b) KORSAR posttest

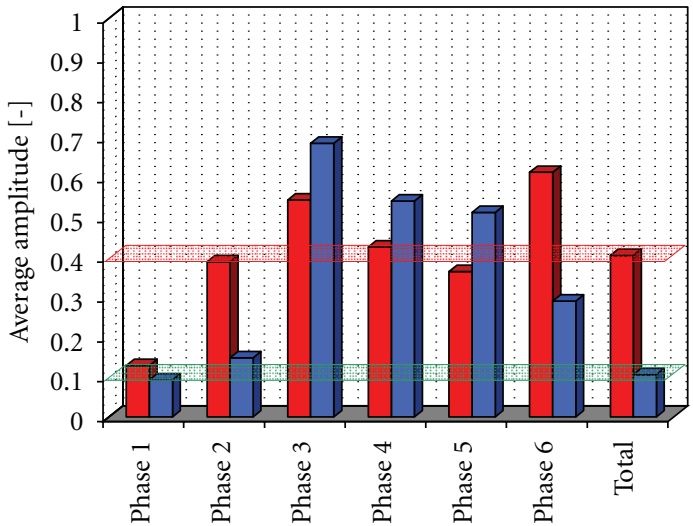

(d) TECH-M posttest

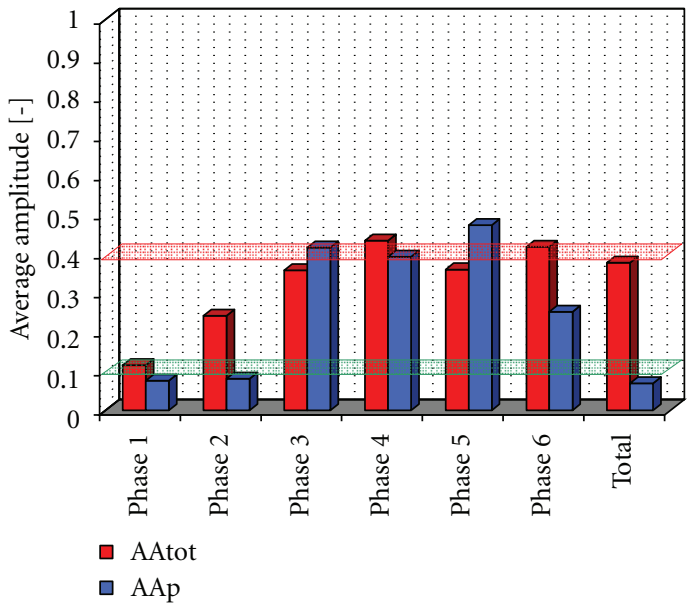

(f) RELAP5-3D posttest

(e) ATHLET posttest

FIGURE 7: FFTBM application: quantitative accuracy evaluation of primary pressure, and total for detail of each phenomenological window and overall transient. 
the method are usually focused on two values: the average amplitudes of the primary pressure and of the global (or total) response.

Figure 6 summarizes the average amplitudes of the 18 selected parameters for each code calculation. Figure 7 provides the primary pressure amplitudes and total average amplitudes as function of each phenomenological windows, according to the description of the test.

The following main conclusions are derived by the quantitative evaluation of the results [15].

(i) Three out of six code applications (ATHLET, RELAP5-3D, and TECH-M) have an average amplitude of the primary pressure equal to or lower than 0.1 , which indicate high accuracy of the results. Among these, it should be highlighted the TECH-M simulation is a pretest. The KORSAR and the TECH$\mathrm{M}$ (posttest) primary pressure trends are very close to this threshold.

(ii) Poor accuracies are calculated for the pressure drops (the AA value is larger than 1), as showed in Figure 6 . The parameters considered are the pressure drop trends across the core, the upper plenum (including the upper head), and the loop seal number 4. These parameters are qualitatively predicted by the ATHLET, REALP5, and TECH-M (posttest) simulations.

(iii) The primary pressure and the total average amplitudes are lower during the first $100 \mathrm{~s}$ (PhW 1 and 2, according to Section 3.2), see Figure 7.

(iv) Two out of six code applications (ATHLET, RELAP53D) showed a good prediction of the experiment, having a total average amplitude lower than 0.4 . The TECH-M simulation evidenced a fair prediction of the experiment, having a total average amplitude between 0.4 and 0.5 .

\section{Conclusions}

The OECD/NEA PSB-VVER project provided unique and useful experimental data for code validation by the scaleddown integral test facility PSB-VVER. In this framework, four participants and three different institutions simulated the test 5a (identification CL-2x100-01), which is the last experiment of the project test matrix. The Western (i.e., ATHLET and RELAP5-3D) and Eastern (KORSAR and TECH-M) advanced computer codes were applied in this context. The initiating event is the double-ended guillotine break in cold leg.

The objective of the activity is to collect, analyze, and document the numerical activity (posttest) performed by the participants, describing the performances of the codes simulations and their capability to reproduce the relevant thermal-hydraulic phenomenaobserved in the experiment.
The objective is fulfilled through comprehensive comparisons based on the following steps:

(i) comparison of the features of the analytical models applied,

(ii) verification of the code performance "at steady state level,"

(iii) assessment of the code performance at "on transient level" based on a qualitative and quantitative (FFTBM) accuracy evaluation of the results.

The analysis of the results demonstrates the following:

(i) all code runs were able to predict the primary pressure trend with satisfactory accuracy;

(ii) the core cladding temperature was predicted by all posttest analyses. In particular, the maximum cladding temperature was generally overestimated (posttest) with the exception of the ATHLET simulation that highlighted an excellent accuracy;

(iii) the primary mass inventories predicted by the simulations resulted in general lower than the experimental (indirect) measurement.

The application of the FFTBM, related to the quantification of the accuracy, showed the following:

(i) almost all code simulations have an average amplitude of the primary pressure equal or lower 0.1 and the others are very close to this threshold,

(ii) all code simulations showed a good prediction of the experiment (total average accuracy lower than 0.4 ) or a fair prediction $\left(0.4<\mathrm{AA}_{\text {tot }}<0.5\right)$,

(iii) the parameter trends of the pressure drops during the transient and the timing of the final cladding temperature excursions affected the total average by increasing the final values.

In conclusion, the availability of the experimental data and the present benchmarking activity brought to the following achievements.

(i) The experiment PSB-VVER test 5a, executed in the largest ITF currently available for VVER-1000 type reactors, contributes to extend the experimental database for code validation.

(ii) The applications of the numerical models represent an enlargement of the validation activity for computer codes. In this connection, the comparison of Western and Eastern computer codes represent a further valuable achievement. 


\section{Nomenclature}

$\mathrm{AA}_{\mathrm{pp}}: \quad$ Average amplitude primary pressure

$\mathrm{AA}_{\mathrm{tot}}$ : $\quad$ Average amplitude total

ACC: Hydraulic accumulator

CCFL: Counter current flow limiting

CL: $\quad$ Cold leg

CSNI: Committee on the Safety of Nuclear

Installations

DC: $\quad$ Downcomer

DP: $\quad$ Pressure drop

ECCS: $\quad$ Emergency core cooling system

EDO-GP: EDO-Gidropress (the VVERs designer)

EoT: $\quad$ End of transient

ESA: Hexagon

FFTBM: Fast Fourier transform-based method

GP: Gidropress (the VVERs designer)

GRS: Gesellschaft für Anlangen-und

Reaktorsicherheit

HL: Hot leg

HPIS: $\quad$ High-pressure injection system

INL: Idaho National Labs

ITF: Integral test facility

LB-LOCA: Large break-loss of coolant accident

LOCA: Loss of coolant accident

LP: $\quad$ Lower plenum

LPIS: $\quad$ Low-pressure injection system

LS: $\quad$ Loop seal

MCP: $\quad$ Main coolant pump

NEA: $\quad$ Nuclear Energy Agency

NRI: $\quad$ Nuclear Research Institute Czech Republic

OECD: Organization for Economic Cooperation and Development

PCT: $\quad$ Peak cladding temperature

PhW: $\quad$ Phenomenological windows

PMI: $\quad$ Primary mass inventory

PRZ: $\quad$ Pressurizer

RCS: $\quad$ Reactor coolant system

RPV: $\quad$ Reactor pressure vessel

RTA: Relevant thermalhydraulic aspect

SBLOCA: Small break loss of coolant accident

SG: $\quad$ Steam generator

SoT: $\quad$ Start of transient

TH-SYS: Thermal-hyrdraulic system

UH: Upper head

UNIPI: Università di Pisa

UP: $\quad$ Upper plenum

VVER: Russian-designed pressurized water reactor

WF: Weight frequency.

\section{Acknowledgments}

The Authors would like to acknowledge the OECD Nuclear Energy Agency (NEA) that promoted the PSB-VVER project, Jean Gauvain who managed the project, and the Institutions involved, which contributed to develop a common understanding and to promote an exchange of knowledge.

\section{References}

[1] Group of Experts of the NEA/CSNI, "Validation matrix for the assessment of thermal-hydraulic codes for VVER LOCA and transients," NEA/CSNI/R(2001)4, 2001.

[2] N. Aksan, D. Bessette, I. Brittain et al., "CSNI code validation matrix of thermal-hydraulic codes for LWR LOCA and transients," OECD/NEA-CSNI Report 132, 1987.

[3] A. Annunziato, H. Glaeser, J. Lillington, P. Marsili, c. Renault, and A. Sjöberg, "CSNI integral test facility validation matrix for the assessment of thermal-hydraulic codes for LWR LOCA and transients," NEA/CSNI/R(96)17, 1996.

[4] N. Aksan, F. D'Auria, H. Glaeser, R. Pochard, C. Richards, and A. Sjöberg, "Separate effects test matrix for thermal-hydraulic code validation. Volume I: phenomena characterisation and selection of facilities and tests," NEA/CSNI/R(93)14/Part 1, Paris, 1994.

[5] N. Aksan, F. D'Auria, H. Glaeser, R. Pochard, C. Richards, and A. Sjöberg, "Separate effects test matrix for thermalhydraulic code validation. Volume I: facility and experiment characteristics," NEA/CSNI/R(93)14/ Part 2, Paris, 1994.

[6] O. I. Melikhov, V. I. Melikhov, and I. V. Parfenov, "PSB-VVER test priority for the OECD PSB-VVER project," OECD PSBVVER Project, PSB-VVER Report, PSB-01, EREC, Electrogorsk, Russia, 2003.

[7] O. Melikhov, I. Elkin, I. Lipatov et al., "Report about PSBVVER description (including measurement system)," OECD PSB-VVER Project, PSB-VVER Report, PSB-03, EREC, Electrogorsk, Russia, 2003.

[8] O. I. Melikhov, I. V. Elkin, I. A. Lipatov et al., "Post-test full experimental data report (test 1)," OECD PSB-VVER Project Report PSB-08, EREC, Electrogorsk, Russia, 2003.

[9] O. I. Melikhov, I. V. Elkin, I. A. Lipatov et al., "Post-test full experimental data report (test 2)," OECD PSB-VVER Project Report PSB-15, EREC, Electrogorsk, Russia, 2003.

[10] O. I. Melikhov, I. V. Elkin, I. A. Lipatov et al., "Post-test full experimental data report (test 3)," OECD PSB-VVER Project Report PSB-18, EREC, Electrogorsk, Russia, 2004.

[11] F. D'Auria, M. Cherubini, G. M. Galassi, and N. Muellner, "Analysis of measured and calculated counterpart test data in PWR and VVER 1000 simulators," Nuclear Technology and Radiation Protection, vol. 20, no. 1, pp. 3-15, 2005.

[12] O. I. Melikhov, I. V. Elkin, I. A. Lipatov et al., "Post-test full experimental data report (test 4)," OECD PSB-VVER Project Report PSB-26, EREC, Electrogorsk, Russia, 2005.

[13] O. I. Melikhov, I. V. Elkin, I. A. Lipatov, M. P. Gashenko, and A. V. Kapustin, "Final AE comparison report," OECD PSB-VVER Project report PSB-29, EREC, Electrogorsk, Russia, 2008.

[14] I. V. Elkin, I. A. Lipatov, A. V. Kapustin et al., "Proposal teport test 5: large cold leg break," OECD PSB-VVER Project. PSBVVER Report, PSB-28, EREC, Electrogorsk, Russia, 2008.

[15] A. Del Nevo, M. Adorni, F. D’Auria et al., "Benchmark on OECD/NEA PSB-VVER project test 5A: LB-LOCA transient in PSB-VVER facility," DIMNP NT 638(08) Rev. 2, University of Pisa, Pisa, Italy, 2009.

[16] I. V. Elkin, G. I. Dremin, I. A. Lipatov, and S. A. Galchanskaya, "Report about PSB-VVER heat losses, OECD PSB-VVER project,” PSB-VVER REPORT, PSB-04, EREC, Electrogorsk, Russia, 2003.

[17] I. V. Elkin, M. A. Berezutskaya, G. I. Dremin, I. A. Lipatov, and I. A. Antonova, "Report about PSB-VVER hydraulic losses," OECD PSB-VVER Project, PSB-VVER Report, PSB-05, EREC, Electrogorsk, Russia, 2003. 
[18] I. V. Elkin, A. I. Suslov, and O. I. Melikhov, "Experimental data deport test 5a (version 1)," OECD PSB-VVER Project, PSBVVER REPORT, PSB-31, EREC, Electrogorsk, Russia, 2008.

[19] F. D’Auria, A. Bousbia-Salah, A. Petruzzi, and A. Del Nevo, "State of the art in using best estimate calculation tools in nuclear technology," Nuclear Engineering and Technology, vol. 38, no. 1, pp. 11-32, 2006.

[20] M. Bonuccelli, F. D’Auria, N. Debrecin, and G. M. Galassi, "A methodology for the qualification of thermalhydraulic code nodalizations," in Proceedings of the 6th International Topical Meeting on Nuclear Reactor Thermalhydraulics (NURETH'93), Grenoble, France, October 1993.

[21] R. Bovalini, F. D’Auria, and M. Leonardi, "Qualification of the fast Fourier transform based methodology for the quantification of thermalhydraulic code accuracy," DCMN Report, NT 194 (92), Pisa, Italy, 1992.

[22] W. Ambrosini , , F. D'Auria, R. Bovalini, and F. D'Auria, "Evaluation of accuracy of thermal-hydraulic code calculations," Energia Nucleare, vol. 7, no. 2, pp. 5-16, 1990.

[23] A. Prosek, F. D'Auria, and B. Mavko, "Review of quantitative accuracy assessments with fast Fourier transform based method (FFTBM)," Nuclear Engineering and Design, vol. 217, no. 1-2, pp. 179-206, 2002.

[24] N. Muellner , E. , A. , F. D’Auria, E. Seidelberger, A. Del Nevo, and F. D'Auria, "Application of the fast Fourier transform based method (FFTBM) to assist in the qualification process of for the PSB-VVER1000 relap5," in Proceedings of the International Conference Nuclear Energy for New Europe 2005, vol. CD, Bled, Slovenia, September 2005. 

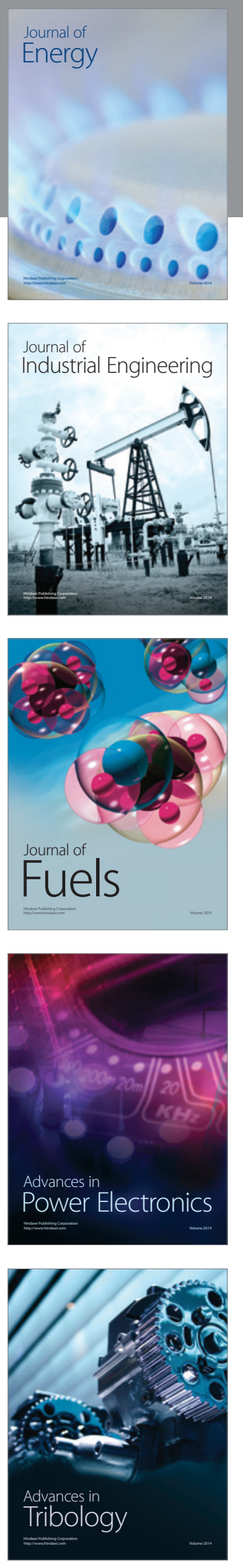
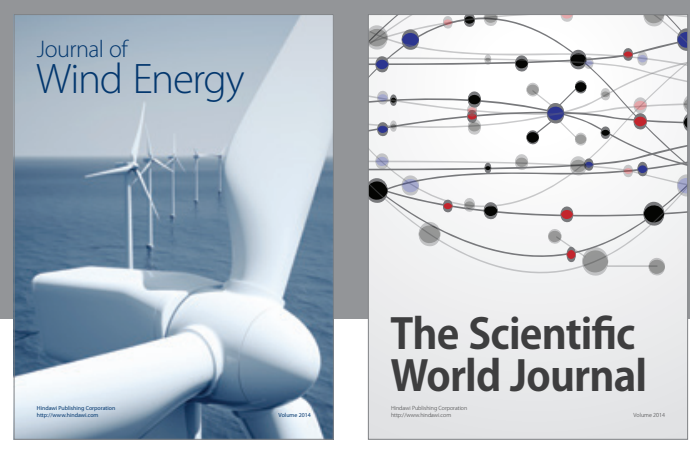

The Scientific World Journal

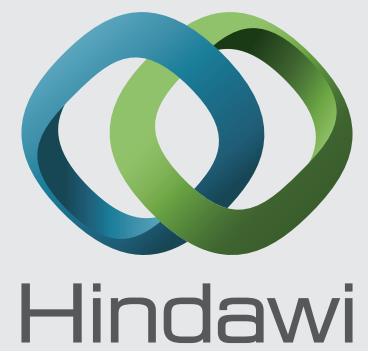

Submit your manuscripts at http://www.hindawi.com
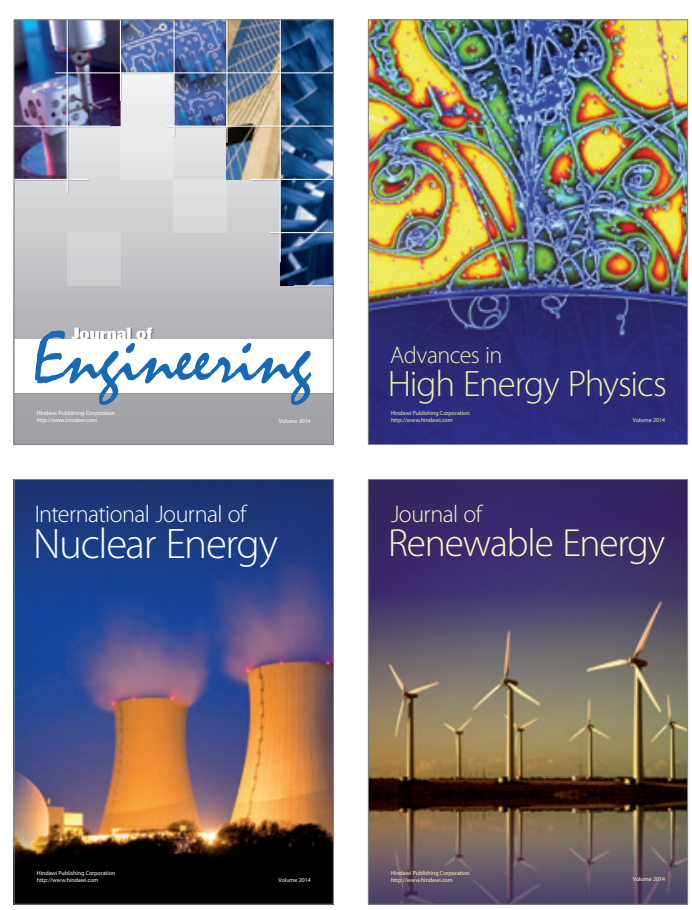

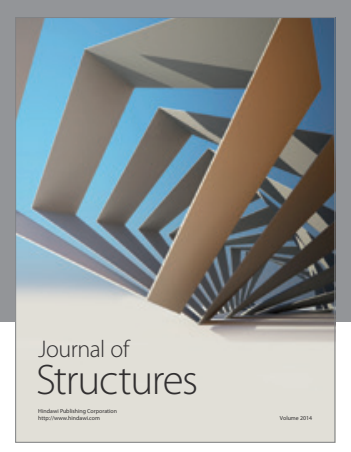

Rotating
Mechinery
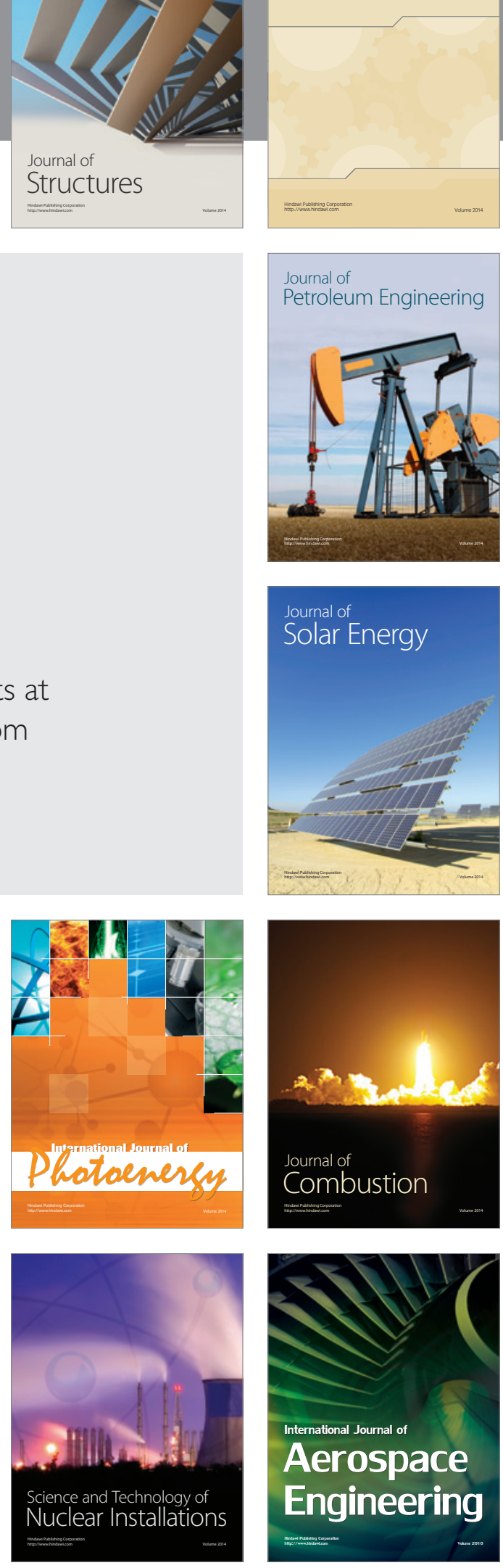